\title{
DEBATE
}

\section{NIGERIAN ACADEMIA AND THE POLITICS OF SECRECY}

\author{
Olukoya Ogen and Insa Nolte
}

In this issue, Jeremiah Arowosegbe makes a number of valid and important observations about the challenges facing the humanities and social sciences in Nigeria. But while he recognizes the importance of the political sphere by discussing the unequal and asymmetric landscape of global knowledge production, he locates most problems of knowledge production in Nigeria within the academy. Focusing on individual and generational responsibility and morality, Arowosegbe also suggests that recent generations of Nigerian academics have been 'complacent and nonchalant' in their engagement with global theoretical and methodological debates, and thus bear responsibility for the apparent decline of Nigerian academia.

Drawing on the shared experience of research based at both UK and Nigerian universities, ${ }^{1}$ we argue that the current state of research in the humanities and social sciences is not primarily the result of the self-indulgence of Nigerian academics. Certainly, academic productivity is limited by sometimes autocratic forms of leadership and management. However, widely unproductive relations between university management and academic unions, the reduction of internal diversity within many universities, and a studied ignorance of students' legitimate

\footnotetext{
Olukoya Ogen is the Provost of Adeyemi College of Education, Ondo, Nigeria. Olukoya is also a Professor of History at Osun State University, Oshogbo; an Associate Expert at the UNESCO Institute for African Culture and Understanding, Olusegun Obasanjo Presidential Library, Abeokuta; and a Visiting Senior Research Fellow at the Department of African Studies and Anthropology, University of Birmingham, UK. He has published widely on Nigerian history and held a range of UK- and US-based fellowships. He is the Nigerian Coordinator of a European Research Council (ERC) project entitled 'Knowing Each Other: Everyday Religious Encounters, Social Identities and Tolerance in Southwest Nigeria'. Email: koyaogen@gmail.com INSA NOLTE is a Reader in the Department of African Studies and Anthropology, University of Birmingham, UK, and a Visiting Research Professor at Osun State University, Oshogbo, Nigeria. She is the Reviews Editor of Africa: Journal of the International African Institute, and the Vice President of the African Studies Association of the UK for 2014-16. Her research focuses on the importance of everyday encounters and interpersonal relationships for wider social and political processes in Nigeria. She is the Principal Investigator of the ERC 'Knowing Each Other' project, which explores the way in which differences and encounters between Yoruba Muslims, Christians and traditionalists inform social identities shaped by locality, gender, and generation. Email: M.I.Nolte@bham.ac.uk

${ }^{1}$ Since 2012, we have been working together on the ERC 'Knowing Each Other' grant (grant no. 283466), which enabled us to build up a team of junior researchers based at the University of Birmingham, UK, and Osun State University, Nigeria, in order to pursue a multidisciplinary approach to the study of religious difference in everyday life, including the first large-scale ethnographic survey on religion in south-west Nigeria.
}

(C) International African Institute 2016. This is an Open Access article, distributed under the terms of the Creative Commons Attribution licence (http://creativecommons.org/licenses/by/4.0/), which permits unrestricted re-use, distribution, and reproduction in any medium, provided the original work is properly cited. 
interests at both undergraduate and graduate levels suggest that the real problems lie beyond the university sector. As lack of funding and authoritarianism have destroyed previously democratic and participatory structures, the transformation of the Nigerian university sector points to the emergence of 'private indirect government' beyond the campuses (Mbembe 2001).

The privatization of the state has undermined the foundations on which current forms of academic knowledge production are based, and the state of the academy reflects the culture of secrecy that dominates the polity. In Nigeria's current political economy, government relies on the tight control of information otherwise considered to be in the public interest. While the state's decreasing investment in producing basic statistical and demographic information since the 1970s has been partly due to access and capacity problems (Jerven 2013), it has primarily reflected the attempt to avoid political demands on the basis of such information. For example, the lack of reliable large-scale data on Nigerians' religious identification means that the widespread assumption that the country has a slight Muslim majority - based on numbers obtained during the 1960s - has not been re-examined for decades, clearly with a view to maintaining the status quo.

Like their colleagues in many other sub-Saharan African states, social scientists from Nigeria thus have had to pursue their work without access to the raw materials that would have enabled them to relate to wider debates. The state's lack of engagement with modern techniques of governmentality has obviously limited Nigerian participation in engagements with quantitative methods that have transformed the social sciences. Moreover, and perhaps ironically, it has silenced Nigerian participation in theoretical debates about the relationship between knowledge production and power. As a result, a large amount of social science research in Nigeria relies on newspaper journalism and small-scale case studies. Such research appeals to wider academic audiences primarily where its content engages with existing global debates on Africa, but it rarely allows Nigerian academics to challenge the underlying assumptions of these debates.

The privatization of information has also had a crippling effect on historical research. While many important files of the colonial period are held outside Africa, those that are based on the continent tend to decline over time, and not only because of often dismal storage conditions. In various Nigerian archives we have consulted, files relating to land, political authority and identity had disappeared or were missing sections. Where files exist, personal experience suggests that it is not unusual for researchers to be put under considerable pressure not to investigate issues that might be seen as challenging the interests of powerful individuals. At the same time, archival resources on the postcolonial period are extremely limited because politicians routinely take home the most important files from their tenure to ensure security. As a result there are, almost fifty-five years after independence, very few local archival sources available to the historian of postcolonial Nigeria, and indeed many other African countries (cf. Allman 2013). Often, the political pressures that limit their access to relevant sources also restrain the ability of African historians to engage with wider historiographical debates.

In contrast to these examples, the relative success of academics in fields such as literature, languages, music and other forms of local intellectual and artistic production illustrates that, where access to empirical material is less likely to be subjected to privatization, Nigerian scholars continue to make important 
contributions to wider debates. Yet many promising scholars are nonetheless subject to the politics of secrecy. There are many inspiring personal and professional examples among Nigeria's senior academics, but some senior colleagues have become so frustrated with the local possibilities of intellectual production that they have increasingly focused on empire building within their institutions. In some universities, information about grants, fellowships, publication opportunities and international networks is made accessible only to the political loyalists and personal confidants of those in the know, while promising scholars unwilling to join such patronage networks are prevented from building their careers through intentional misinformation.

Given the importance of mutual engagement in the field of African studies, Africanists based in the global North could also have done more to maintain close ties with their Nigerian colleagues. Faced with the growing difficulties of conducting research in Nigeria, several scholars who began their research careers there later changed the geographical focus of their work, while others have invested increasingly in theoretical and philosophical reflection. As if imitating the country's growing consultancy culture, international academic collaborations often rely on their Africa-based partners - who, after all, are already used to the difficulties of local fieldwork - to collect empirical material to address the more general, abstract and theoretical concerns raised by their Northern-based counterparts. Faced with growing institutional pressures themselves, many scholars outside Nigeria believe that they do not have the time to engage in the longterm exchanges and collaborations that are needed to produce truly collaborative work.

\section{WHAT CAN BE DONE?}

Despite the many problems faced by Nigerian academia, the current changes in its university sector offer some opportunities for transformation. The establishment of private universities has enabled many young Nigerian scholars to find lecturing appointments even before they have completed their doctorates, unlike their counterparts in the UK or US. The expansion and rejuvenation of Nigerian academia is a potentially powerful driver for an increased re-engagement with scholars in the global North and beyond, and young scholars are increasingly encouraged to seek backing from the Council for the Development of Social Science Research in Africa (CODESRIA) and, especially if they are based at state and federally owned institutions, from the Nigerian Tertiary Education Trust Fund (TETFund).

Other opportunities for younger scholars are provided by well-networked Nigerian academics based both within Nigeria and abroad, who encourage the (re-)engagement of Nigerian academia with its global academic peers. For example, the workshops organized by the Nigerian Humanities Society (NHS) have made an important contribution to the success of Nigerian scholars as applicants to international and potentially collaborative research fellowships. ${ }^{2}$ Equally

\footnotetext{
${ }^{2}$ These include the American Council of Learned Societies (ACLS), British Academy (BA) Visiting Fellowships, Newton Fellowships, the German Academic Exchange Service and the Alexander von Humboldt Foundation, among others.
} 
importantly, the renewed realization of Northern-based Africanists that the potential for innovation within their fields depends on the critical engagement of African scholars with ongoing discourses has contributed to a range of supportive and potentially collaborative programmes. ${ }^{3}$ While these initiatives suggest that Northern scholars remain privileged even in the reflection on Africa's academic disorder, we consider Jeremiah Arowosegbe's contribution to this volume - and the journal's decision to publish it - an important step in the right direction (cf. Barber 2008).

Undoubtedly, Nigerian university leaders need to make a clearer commitment to supporting younger scholars. Senior academic staff must be asked to demonstrate leadership through the sharing of information and skills. Universities must also institutionalize departmental research culture through support for female and 'minority' staff, regular seminars and outreach events, and an emphasis on the importance of younger colleagues' and doctoral students' research and writing. In addition to setting up and monitoring relevant programmes through the National Universities Commission, such activities can be incentivized through a reformulation of promotions criteria (British Academy and Association of Commonwealth Universities 2011). Going beyond the present focus on the counting of personal publications, assessors should also take into account the facilitation, by academics at all levels, of younger scholars' success through supervision, mentoring, joint publication, fellowships and access to research funds. Beyond Nigeria, the formal recognition by Northern universities that Africanist research must include mentoring relationships and collaboration with Africabased scholars would make an important contribution to the field.

But most importantly, Nigeria's new generation of scholars will require a broad societal commitment to the production of, and open access to, the forms of information on which knowledge production is based. This must include a greater investment in the production of information and data relevant to academic reflection and analysis, as well as greater control of public material and its preservation. Research capacity must be retained and enhanced through support for new and existing archives, the digitization of files, and widespread access for Nigerian academics to existing databases of scholarly research. Given the obvious limitations of Africanist research produced primarily outside Africa, it is in the interests of African and Africanist scholars both in Africa and in the global North and beyond to support this process both personally and politically.

\footnotetext{
${ }^{3}$ In 2007, the BA and the Association of Commonwealth Universities (ACU), in consultation with the Royal African Society and the African Studies Association of the UK (ASAUK), began to reflect on frameworks for Africa-UK research collaboration, also referred to as 'the Nairobi process' (cf. Harle 2007). Simultaneously, the BA launched a scheme to support collaborative, mutually beneficial research and capacity-enhancing partnerships between UK and African individuals and institutions (the UK-Africa Partnerships, now widened to a global scheme known as the International Partnership and Mobility Scheme). Like many Northern-based Africanist organizations, the ASAUK offers a range of grants for African scholars attending their conferences. Supported by the BA and a range of Africanist journals, the ASAUK runs a regular programme of writing workshops to support African scholars wanting to submit a piece of research for publication in international journals.
} 


\section{REFERENCES}

Allman, J. (2013) 'Phantoms of the archive: Kwame Nkrumah, a Nazi pilot named Hanna, and the contingencies of postcolonial history-writing', American Historical Review 118 (1): 104-29.

Barber, K. (2008) 'Editorial', Africa 78 (3): 327-33.

British Academy and Association of Commonwealth Universities (2011) Foundations for the Future: supporting the early careers of African researchers. London: British Academy.

Harle, J. (2007) Frameworks for Africa-UK Research Collaboration in the Social Sciences and Humanities: African university perspectives. A report to The British Academy by The Association of Commonwealth Universities. London: Association of Commonwealth Universities.

Jerven, M. (2013) Poor Numbers: how we are misled by African development statistics and what to do about it. Ithaca NY: Cornell University Press.

Mbembe, A. (2001) On the Postcolony. Berkeley, Los Angeles CA and London: University of California Press. 